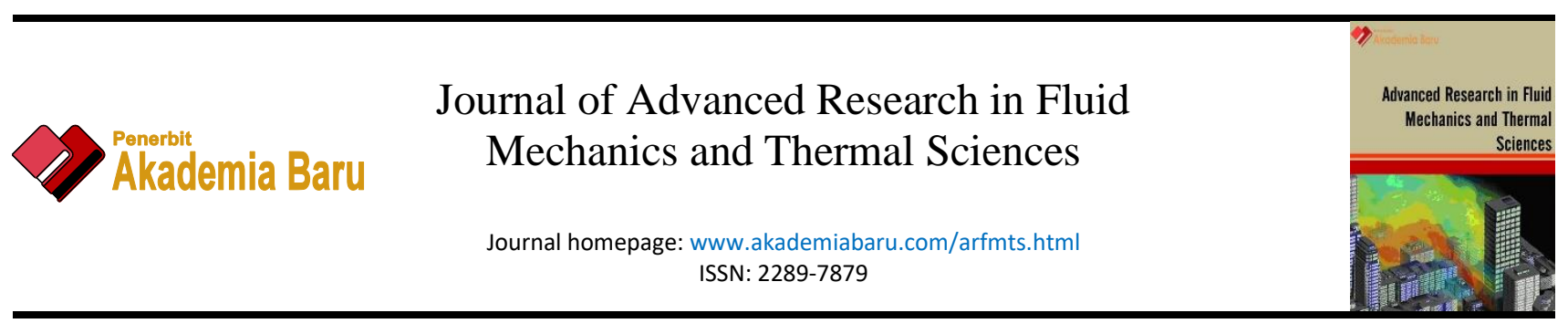

\title{
Analysis of Optimum Thickness of Glass Wool Roof Thermal Insulation Performance
}

\author{
Mohammed W. Muhieldeen ${ }^{1,}{ }^{*}$, Lim Zhen Yang ${ }^{1}$, Lim Chong Lye ${ }^{2,3, *}$, Nor Mariah Adam ${ }^{3,4}$

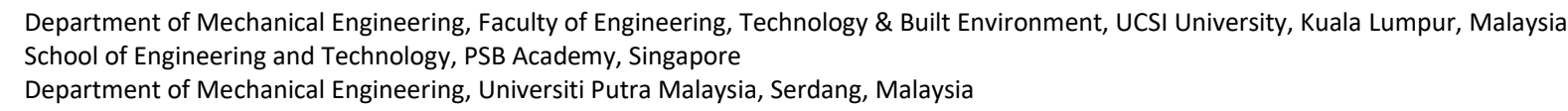

\section{ARTICLE INFO ABSTRACT}

\section{Article history:}

Received 3 June 2020

Received in revised form 15 September 2020

Accepted 23 September 2020

Available online 23 October 2020

\begin{abstract}
Countries in south east Asia are mostly experiencing tropical climate conditions. Therefore, the use of the air conditioning has been increased to reduce the tension and achieve thermal comfort inside the buildings. In order to reduce the energy consumption, thermal insulation has been introduced to lower down the indoor temperature. The main objective of this study is to determine the optimum thickness of the glass wool insulation. To conduct the study, a wooden room model is built based on the classroom that located at one of the Malaysian universities. The thicknesses of the glass wool insulation used in the experiment is $25 \mathrm{~mm}$ (one layer), $50 \mathrm{~mm}$ (two layers) and $75 \mathrm{~mm}$ (three layers). According to the results, the maximum temperature reduction for one layer of insulation is $1.0^{\circ} \mathrm{C}$. Two layers of insulation reduces the indoor temperature by $1.3^{\circ} \mathrm{C}$ followed by the reduction of $1.5^{\circ} \mathrm{C}$ after applying three layers of insulation. The convection coefficient outside and inside is determined to calculate the heat flux of the roof with different insulation thickness. The heat flux gained by the roof reaches the highest value at $1 \mathrm{pm}$ which is $0.648 \mathrm{~W} / \mathrm{m}^{2}$ without insulation. The heat flux has been reduced to $0.629 \mathrm{~W} / \mathrm{m}^{2}$ after applying one layer of glass wool insulation. The heat flux gained by the roof is further reduced to $0.573 \mathrm{~W} / \mathrm{m}^{2}$ and $0.518 \mathrm{~W} / \mathrm{m}^{2}$ when two and three layers of insulation are applied, respectively. Throughout the experiment, the temperature inside the room is reduced with the increase of the insulation thickness. Two layers of glass wool insulation has been selected as the optimum insulation thickness which is validated after performing calculation using the polynomial function as well as the cost analysis. Two layers of glass wool insulation yields a $27.40 \%$ of ROI per annum.
\end{abstract}

Keywords:

Optimum insulation; Energy savings; Tropical climate; Glass wool insulation

\footnotetext{
* Corresponding author.

E-mail address: al-gailani@ucsiuniversity.edu.my

* Corresponding author.

E-mail address: chonglye.lim@psb-acdemy.edu.sg
}

https://doi.org/10.37934/arfmts.76.3.111 


\section{Introduction}

Most of the nations located near to the equator encounter tropical climate conditions. High humidity throughout the year combined with low fluctuations in daytime temperature are the main characteristics of tropical climates. Most of the countries in Asia especially those with tropical climate conditions undergo speedy development [1]. The building sector accounts for $30 \%-40 \%$ of world energy use and it has grown to be the largest energy user [2]. As one of the sectors which consumes an enormous amount of energy, strategy such as energy efficient buildings must be implemented to achieve building energy conservation [3-5]. The energy consumption in HVAC systems is significant in developed countries as it accounts for approximately half of building's energy consumption among other building services. For example, the energy consumption for air conditioning accounts for $28 \%$ of the total consumption in Taiwan during summer times [6-7]. Besides, nearly $40 \%$ of the total residential sector energy consumption is taken up by air conditioning systems in Hong Kong [8]. In Singapore, buildings take up nearly $50 \%$ of total electricity generated and the air conditioning system utilizes up to $30 \%$ of the country's total electricity generation [9]. Roofs take up the maximum direct solar radiation compared to other physical components of a building [10]. Roofs account for nearly $70 \%$ of heat gain of a building [11-12]. The heat gained by the roof during the day is transmitted through and trapped in the attic. The heat will be radiated to the occupants inside the building [13]. This has given rise to higher energy demand for thermal comfort over the last few years. The use of air conditioning is increasing moderately to tackle the thermal discomfort. The good economic conditions and the economic price of air conditioners have made it affordable for the people. However, the energy consumption of the air conditioner is relatively high compared to other electrical appliances. A heat pump in the air conditioner will transfer heat energy from indoors to outdoors. Water vapour from the indoors will be removed which causes the relative humidity in the room to be decreased [14-15]. Therefore, the human comfort experience in indoors is improved. Roofs are the most essential component for the building in reducing the energy usage because the building gain the maximum heat mainly from the roofs. Application of thermal insulation on the roofs can reduce the heat that is transferred into the building. Therefore, roof insulation is effective in reducing heat gained by the building which help to reduce energy use of air conditioning equipment. Rock wool is also used as roof insulation material in the research done by Sisman et al., [16]. The optimum insulation thickness is determined in the following research. The relationship between the cost of insulation and its thickness is linear. Therefore, the extra cost of the insulation materials will not be compensated by the savings in energy consumption beyond the optimum insulation thickness [17].

The objective of this research is to determine the optimum thickness of glass wool insulation based on the temperature reduction of temperature inside the room as well as the polynomial function developed by Indra Mahlia et al., [18]. The cost analysis is performed to determine the energy savings of the optimum thickness of glass wool insulation.

\section{Methodology and Experimental Setup}

In this study, a wooden room model with a dimension of (L: $1.2 \mathrm{~m}, \mathrm{~W}: 0.8 \mathrm{~m}$ and $\mathrm{H}: 0.8 \mathrm{~m})$ is proposed and constructed. Geometry of the wooden room model is shown in Table 1 . The wooden room is constructed based on the classroom located at one of Malaysian universities. The thermal conductivity of the plywood is $0.13 \mathrm{~W} / \mathrm{m} . \mathrm{K}$ according to the manufacturer's standard. The room is connected by using hinges. The glass wool purchased from the market has the thickness of $25 \mathrm{~mm}$ and the thermal conductivity of $0.04 \mathrm{~W} / \mathrm{m} . \mathrm{K}$. 
Table 1

Geometry of the room model

\begin{tabular}{lll}
\hline Component & Dimension & Material \\
\hline Roof & $120 \mathrm{~mm} \times 80 \mathrm{~mm} \times 8 \mathrm{~mm}$ & Three-layered plywood \\
Side wall & $120 \mathrm{~mm} \times 80 \mathrm{~mm} \times 8 \mathrm{~mm}$ & Three-layered plywood \\
Front \& back wall & $80 \mathrm{~mm} \times 80 \mathrm{~mm} \times 8 \mathrm{~mm}$ & Three-layered plywood \\
\hline
\end{tabular}

In order to determine the optimum insulation thickness for the roof of the wooden room model, four types of the configuration of roof are investigated as shown in Table 2. The thermal insulation is installed on top of the roof. The thicknesses of the roof insulation installed are $25 \mathrm{~mm}, 50 \mathrm{~mm}$ and $75 \mathrm{~mm}$ in which a total of three layers of glass wool are applied with an increment of $25 \mathrm{~mm}$. The roof without insulation acts as control of the experiment. Figure 1 to Figure 4 shows the configuration of the roof for Case 1 to Case 4.

Table 2

Configuration of the roof system

\begin{tabular}{lll}
\hline Case & Configuration & Insulation thickness $(\mathrm{mm})$ \\
\hline 1 & Without insulation & 0 \\
2 & One layers of glass wool & 25 \\
3 & Two layers of glass wool & 50 \\
4 & Three layers of glass wool & 75 \\
\hline
\end{tabular}

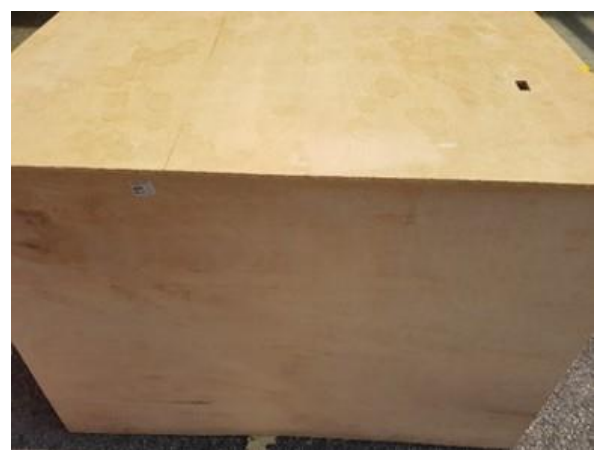

Fig. 1. Case 1 (without insulation)

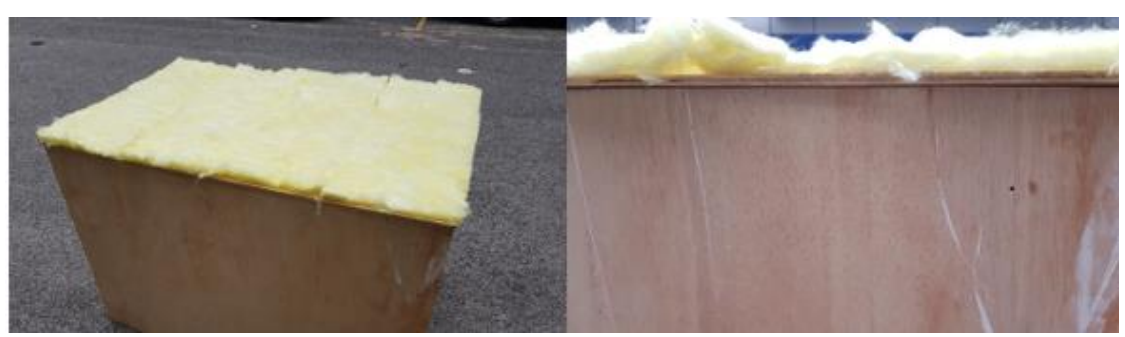

Fig. 2. Case 2 (one layer of glass wool)

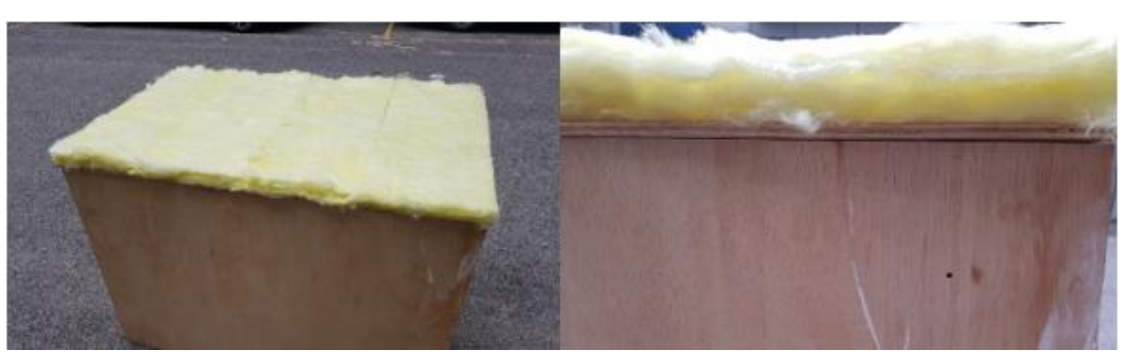

Fig. 3. Case 3 (two layers of glass wool) 


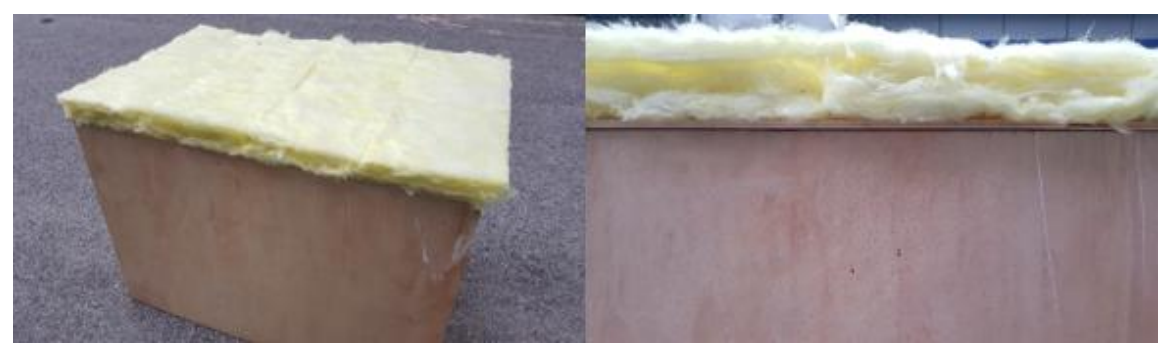

Fig. 4. Case 4 (three layers of glass wool)

The wooden room model is placed under the sun from $10 \mathrm{pm}$ to $4 \mathrm{pm}$ Each configuration of roof (Case 1-4) requires obtaining of 7 sets of data at an interval of 1 hour. Initially, the wooden room model is exposed to solar radiation without using any glass wool insulation. Data such as external roof surface temperature, internal roof surface temperature, surrounding temperature and the temperature inside the room are collected by using handheld digital infrared thermometer and VELOCICALC thermometer as shown in Figure 5 and Figure 6. The experiment is repeated by following the configuration of Case 2, Case 3 and Case 4. After collecting data of Case 1 to Case 4, the experiment is repeated for the next hour.

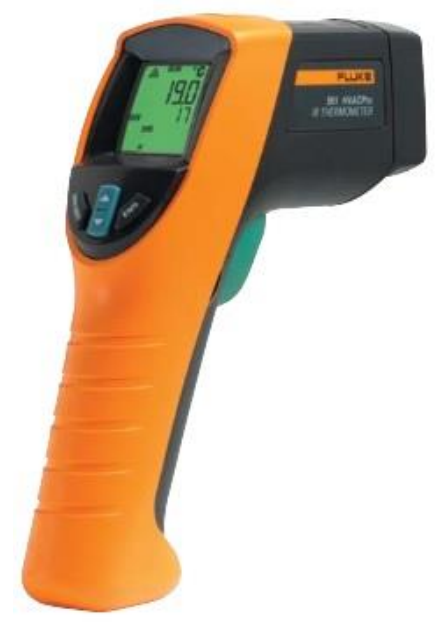

Fig. 5. Infrared thermometer

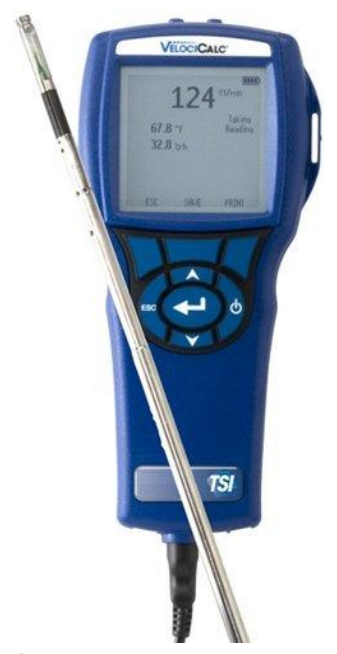

Fig. 6. VELOVCICALC Thermometer

The experimental data are used to calculate Rayleigh number. The calculated Rayleigh number are used to determine the external and internal convection coefficient. The Rayleigh number is calculated as below

$R a_{L}=\frac{g \beta \Delta T L^{3}}{\alpha v}$

where $g$ is the gravitational acceleration, $\beta$ is the volume thermal expansivity, $\Delta T$ is the temperature gradient, $L$ is the characteristic length, $\alpha$ is the thermal diffusivity and $v$ is the kinematic viscosity. On the other hand, the external and internal convection coefficient are calculated through the empirical correlation which has been developed for common external flow geometries as shown below [15].

$\frac{\bar{h} L}{k}=C R a_{L}^{n}$ 
where $\bar{h}$ is the convection coefficient, $L$ is the characteristic length, $k$ is the thermal conductivity, $C$ $=0.59$ and $n=1 / 4$ for laminar flow $\left(10^{4} \leq R a_{L} \leq 10^{8}\right)$ and $C=0.10$ and $n=1 / 3$ for turbulent flow $\left(10^{9}\right.$ $\left.\leq R a_{L} \leq 10^{13}\right)$. The heat flux gained by the roof can be determined as

$q^{\prime \prime}=\frac{T_{\text {outside }}-T_{\text {inside }}}{R_{\text {total }}}$

where $T_{\text {outside }}$ is the surrounding temperature, $T_{\text {inside }}$ is the temperature inside the room and $R_{\text {total }}$ is the total thermal resistance. Total thermal resistance is shown in Eq. (4).

$R_{\text {total }}=\frac{1}{h_{\text {out }}}+\frac{t_{\text {wood }}}{k_{\text {wood }}}+\frac{t_{\text {ins }}}{k_{\text {ins }}}+\frac{1}{h_{\text {in }}}$

where $h_{\text {out }}$ is the outside convection coefficient, $t_{\text {wood }}$ is the thickness of the plywood, $k_{\text {wood }}$ is the plywood's thermal conductivity, $t_{\text {ins }}$ is the thickness of the insulation, $k_{\text {ins }}$ is the thermal conductivity of the insulation and $h_{i n}$ is the inside convection coefficient. The optimum insulation thickness can be obtained by using equation developed by Indra Mahlia et al., [18].

$x_{\text {opt }}=0.0818-2.973 k+64.6 k^{2}$

where $\mathrm{k}$ is the thermal conductivity of the insulation material.

\section{Results and Discussion}

In Figure 7, the comparison between the outside and inside air temperature of the room without applying glass wool insulation are shown. The outside temperature of the room from 10 am to $4 \mathrm{pm}$ is the average of surrounding temperature at that hour. The temperature inside the room increases with respect to outside temperature. The highest temperature inside the room achieves $35.1^{\circ} \mathrm{C}$ at 1 $\mathrm{pm}$. The room temperature reaches its lowest which is $31.0^{\circ} \mathrm{C}$ at 10 am when the experiment starts. The largest temperature difference obtained is $0.7^{\circ} \mathrm{C}$ which is at $1 \mathrm{pm}$ whereas the smallest temperature difference obtained is $0.3^{\circ} \mathrm{C}$ which is at $11 \mathrm{am}$.

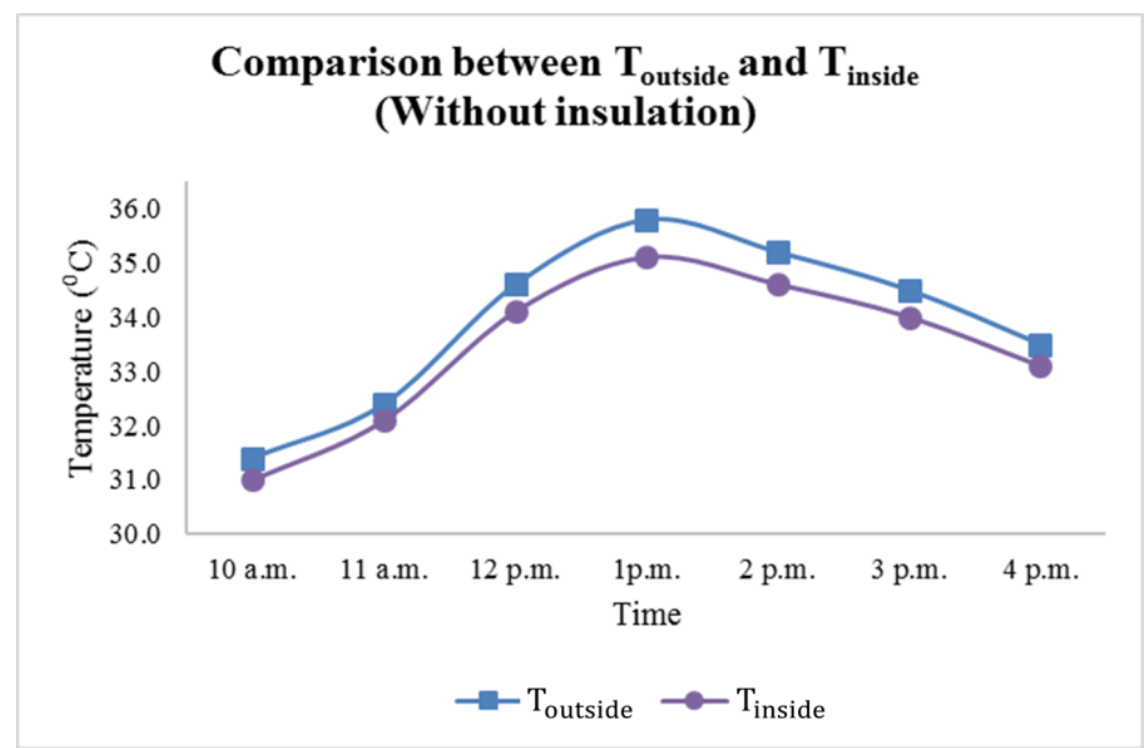

Fig. 7. Comparison between the outside and inside air temperature of the room against time (without insulation) 
After applying one layer of glass wool insulation, the comparison between the outside and inside air temperature of the room model is illustrated in Figure 8. The outside temperature is constant for all the conditions of roof to show the effect of glass wool insulation in reducing the room temperature. The temperature inside the room increases from 10 am which is at $30.9^{\circ} \mathrm{C}$ and continues to rise to $34.8^{\circ} \mathrm{C}$ which is the highest temperature recorded for the inside temperature of the room. A maximum temperature difference of $1^{\circ} \mathrm{C}$ is recorded at $1 \mathrm{pm}$ after applying one layer of glass wool insulation. The lowest temperature difference is obtained at $11 \mathrm{am}$ in which the difference between the surrounding and the temperature inside the room is only $0.4^{\circ} \mathrm{C}$.

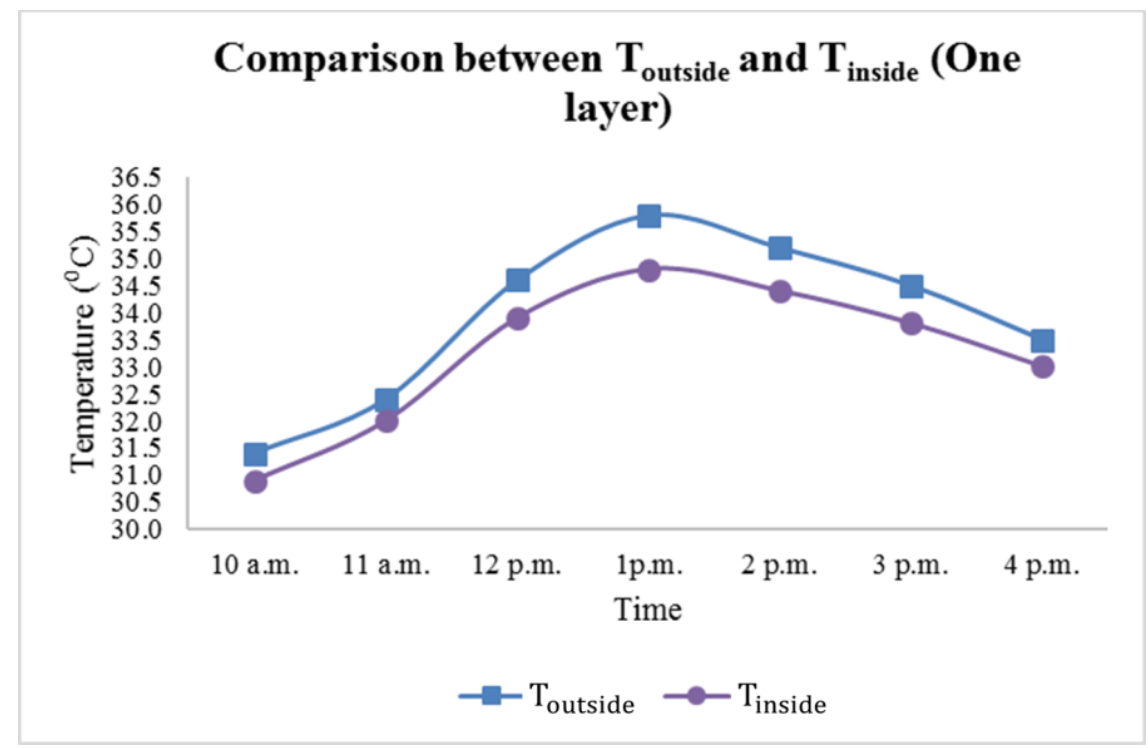

Fig. 8. Comparison between the outside and inside air temperature of the room against time (one layer)

In Figure 9, the comparison between the outside and inside air temperature of the room is more observable when applying two layers of glass wool insulation. The gaps between the outside and inside temperature are larger if compared to the room model without insulation and with one layer of glass wool insulation. The temperature inside the room increases gradually with respect to the outside temperature from 10 am to $1 \mathrm{pm}$. The inside temperature recorded is at $1 \mathrm{pm}$ which is $34.5^{\circ} \mathrm{C}$ whereas the lowest internal temperature of the room is $30.8^{\circ} \mathrm{C}$ at $10 \mathrm{am}$. The temperature difference of $1^{\circ} \mathrm{C}$ and more are recorded from $12 \mathrm{pm}$ to $2 \mathrm{pm}$ which the insulation material plays its role to reduce the temperature of the roof. The reduction of the temperature is the highest at $1 \mathrm{pm}$ which is $1.3^{\circ} \mathrm{C}$. The lowest temperature difference after applying two layers of glass wool insulation is approximately $0.5^{\circ} \mathrm{C}$ at $11 \mathrm{am}$.

The comparison between the outside and inside air temperature of the room after applying three layers of glass wool insulation are plotted in Figure 10. The surrounding temperature of the room starts to rise from $31.4^{\circ} \mathrm{C}$ at 10 am to the highest temperature of $35.8^{\circ} \mathrm{C}$ at $1 \mathrm{pm}$ The inside temperature of the room reaches the highest which is at $34.3^{\circ} \mathrm{C}$ when the outside temperature recorded is the highest. A temperature reduction of $1.5^{\circ} \mathrm{C}$ is achieved at the hottest hour of the day when applying three layers of glass wool insulation on the roof. The temperature difference from 12 $\mathrm{pm}$ to $3 \mathrm{pm}$ ranges from $1.0^{\circ} \mathrm{C}$ to $1.5^{\circ} \mathrm{C}$ while $0.6^{\circ} \mathrm{C}$ is the smallest temperature difference recorded at $11 \mathrm{am}$. Although the use of three layers of glass wool insulation is effective in reducing the temperature inside the room, but the overall temperature reduction is not significant if compared to two layers of glass wool insulation. 


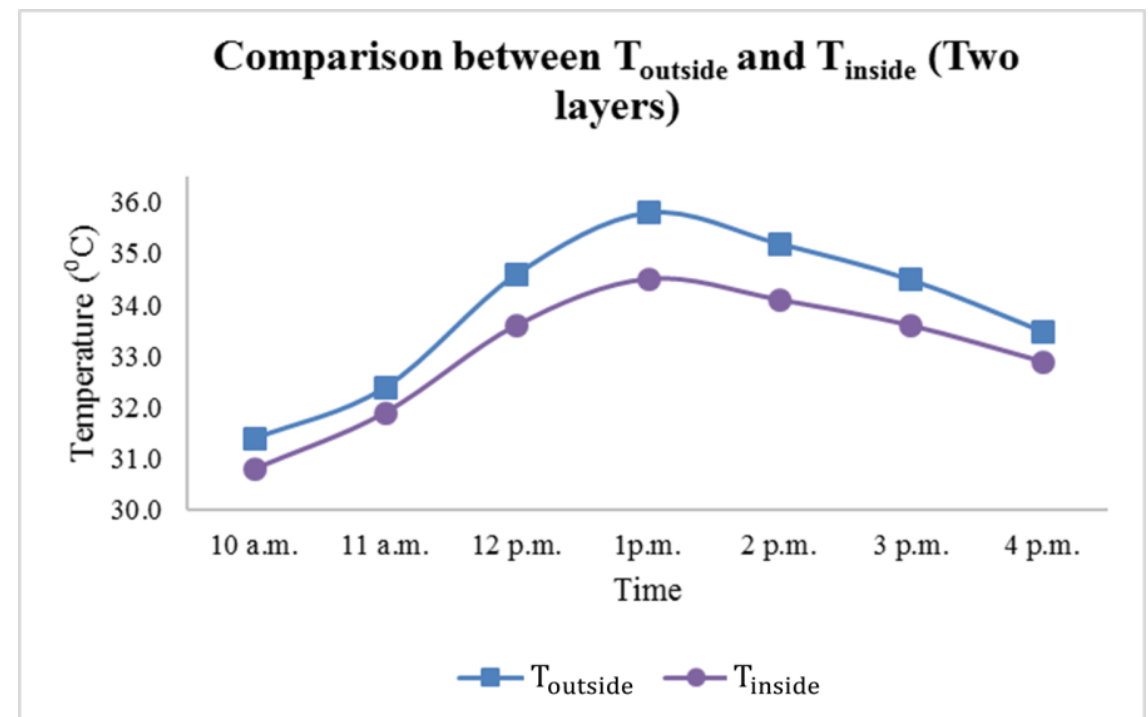

Fig. 9. Comparison between the outside and inside air temperature of the room against time (two layers)

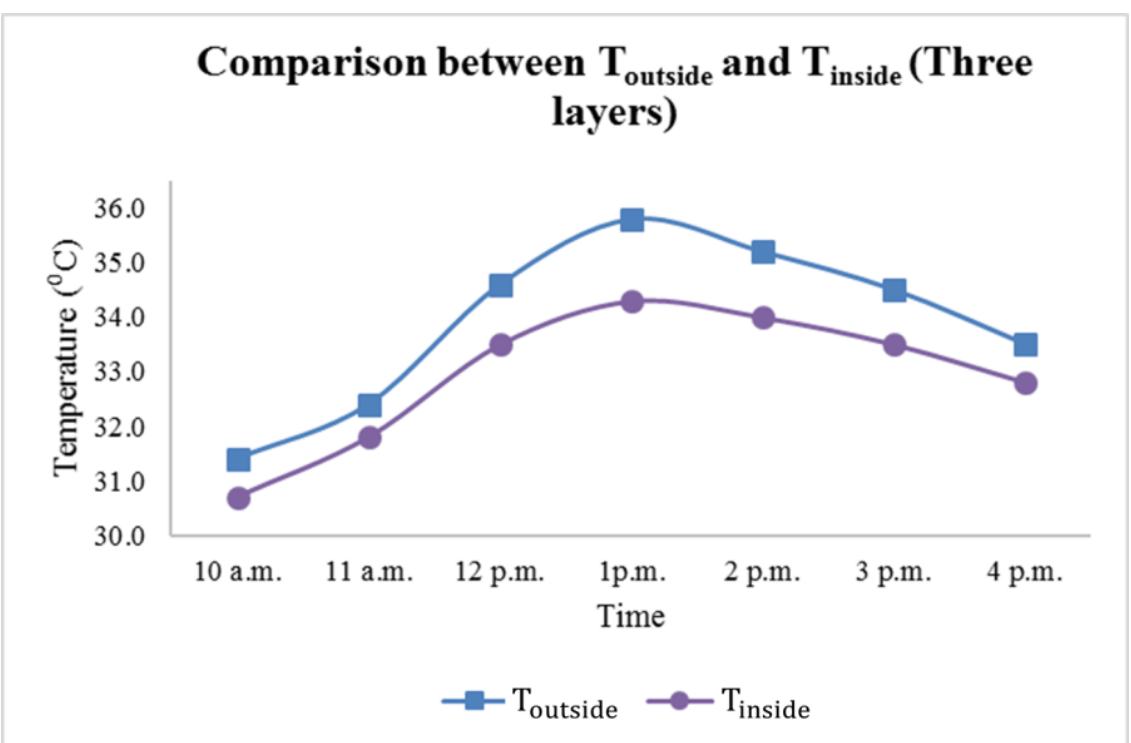

Fig. 10. Comparison between the outside and inside air temperature of the room against time (three layers)

The comparison between the outside and inside temperature of the room for various insulation thickness are combined and shown in Figure 11 whereas the reduction of the temperature inside the room by using different thickness of glass wool insulation is shown in Figure 12. The reduction of temperature from 10 am to $11 \mathrm{am}$ is not significant because the solar radiation received by the roof is not high. According to the study conducted by Qahtan [20], the average dry bulb temperature at $10 \mathrm{am}$ and $11 \mathrm{am}$ are $29.6^{\circ} \mathrm{C}$ and $30.6^{\circ} \mathrm{C}$. Therefore, the use of insulation is not significant when the outdoor temperature of the day is not the maximum. For instance, the reduction of temperature at $10 \mathrm{am}$ for roof without insulation is $0.4^{\circ} \mathrm{C}$ and $0.5^{\circ} \mathrm{C}$ for roof with one layer of glass wool insulation. When two and three layers of glass wool insulation are applied, the temperature is reduced by $0.6^{\circ} \mathrm{C}$ and $0.7^{\circ} \mathrm{C}$, respectively. The reduction of temperature starts to increase significantly with the increase of the thickness of glass wool insulation applied on the roof from $12 \mathrm{pm}$ onwards. The effectiveness of the glass wool insulation is more observable at $1 \mathrm{pm}$ due to the higher solar radiation and outdoor temperature. The average dry bulb temperature reaches the highest at $1 \mathrm{pm}$ which is 
$31.6^{\circ} \mathrm{C}[20]$. The maximum reduction in indoor temperature is recorded at $1.5^{\circ} \mathrm{C}$ when using three layers of glass wool insulation followed by $1.3^{\circ} \mathrm{C}$ with two layers of glass wool insulation. The indoor temperature is also reduced by $1^{\circ} \mathrm{C}$ when using only single layer of insulation. When using three layers of insulation, the temperature reduction is twice the value of the roof without using any insulation which the indoor temperature is reduced by $0.7^{\circ} \mathrm{C}$ when no insulation is being used. Although the temperature reduced by using three layers of glass wool insulation is the highest, it might not be the optimum thickness if considered the cost of insulation material.

The reduction of temperature inside the room becomes less noticeable from $3 \mathrm{pm}$ onwards. The temperature is reduced at a range between $0.4^{\circ} \mathrm{C}$ to $0.8^{\circ} \mathrm{C}$. The average dry bulb temperature is declining to $30.0^{\circ} \mathrm{C}$ at $4 \mathrm{pm}$. Therefore, the reduction of temperature is not significant at $4 \mathrm{pm}$ due to the low temperature variation between indoor and outdoor temperature. A significant contribution to both the surface temperature and the indoor temperature is clearly made by direct solar radiation [20].

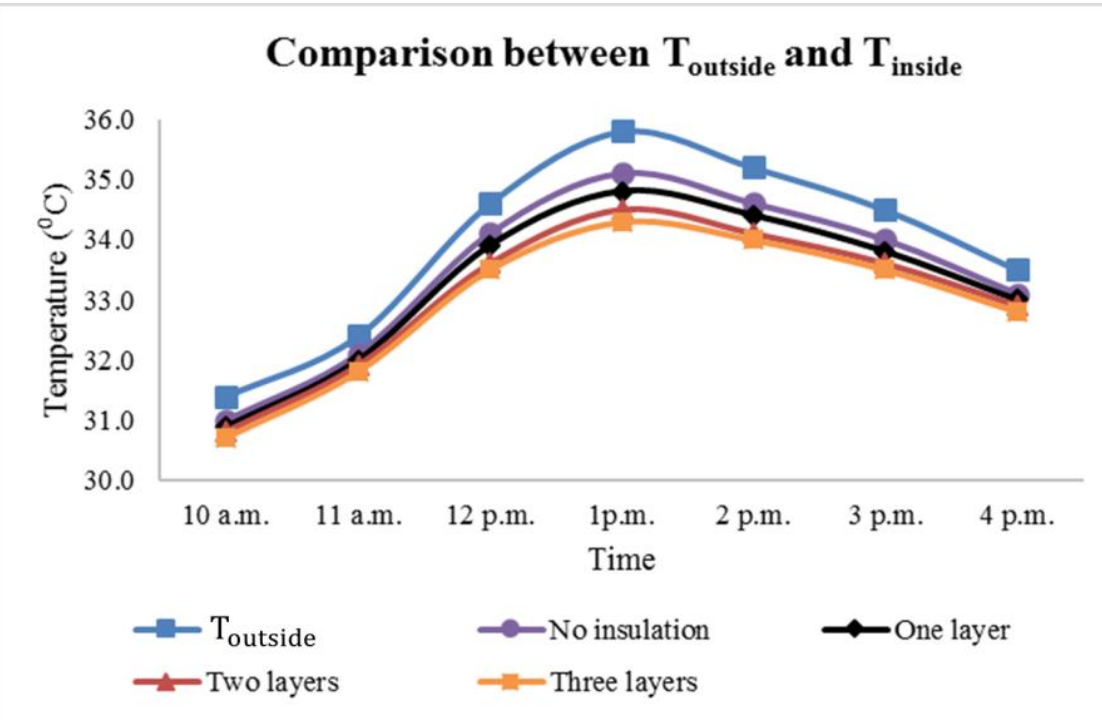

Fig. 11. The comparison between the outside and inside temperature of the room for various insulation thickness

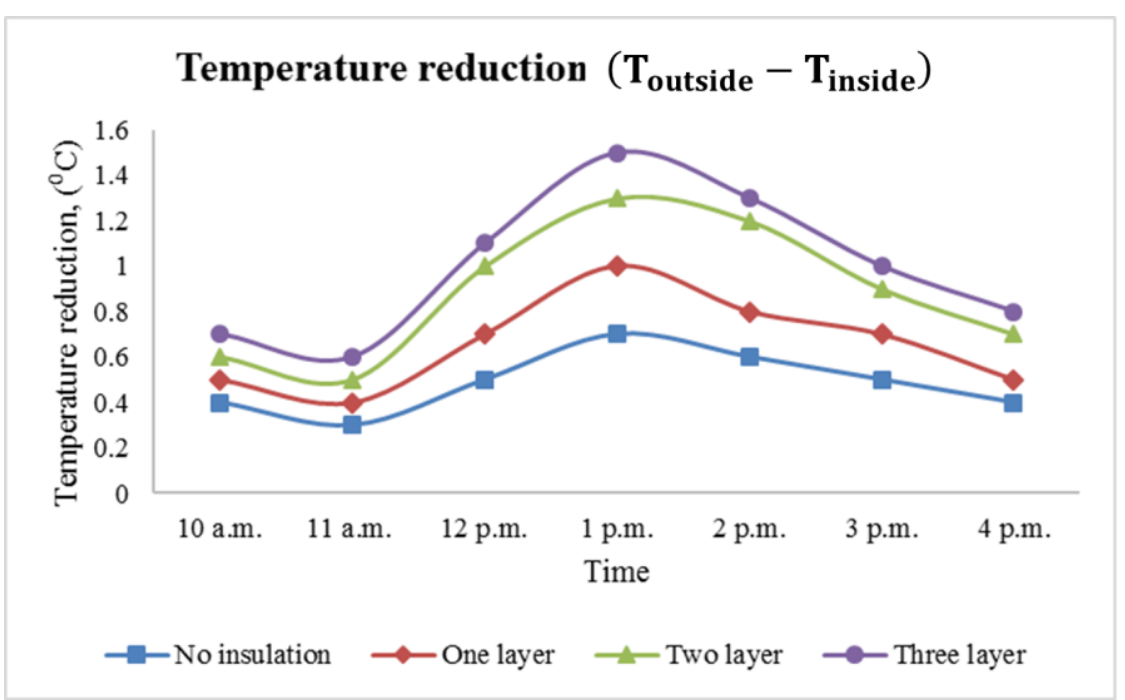

Fig. 12. Temperature reduction of various insulation thickness over time 
The heat flux of the roof for various insulation thickness is calculated and tabulated in Table 3 . The heat flux of the roof at 10 am for different insulation thickness ranges from $0.244 \mathrm{~W} / \mathrm{m}^{2}$ to 0.392 $\mathrm{W} / \mathrm{m}^{2}$. The heat flux of the roof is not high because the solar radiations received hourly at 10 am is $4.1 \mathrm{kWh} / \mathrm{m}^{2}$. The heat flux of the roof for different insulation thickness reaches the highest at $1 \mathrm{pm}$ because the average solar radiation at $1 \mathrm{pm}$ is nearly $5.3 \mathrm{kWh} / \mathrm{m}^{2}$. The heat flux of the roof ranges from $0.518 \mathrm{~W} / \mathrm{m}^{2}$ to $0.648 \mathrm{~W} / \mathrm{m}^{2}$. With the increase in the glass wool insulation thickness, the heat flux is reduced. At $4 \mathrm{pm}$, the heat flux decreases due to low intensity of solar radiation. The heat flux ranges from $0.247 \mathrm{~W} / \mathrm{m}^{2}$ to $0.411 \mathrm{~W} / \mathrm{m}^{2}$. The average solar radiation at $4 \mathrm{pm}$ is low which is 2.2 $\mathrm{kWh} / \mathrm{m}^{2}$ [19]. Although the average solar radiation at $4 \mathrm{pm}$ is low, the heat flux of the roof at $4 \mathrm{pm}$ is still slightly higher than $10 \mathrm{am}$, which is mainly due to the trapped heat inside the room. Table 4 shows the comparison between the roof area of workshop and wooden room model as well as the cost of applying each layer of glass wool insulation.

Table 3

Heat flux of the roof for various insulation thickness

\begin{tabular}{|c|c|c|c|c|c|c|c|c|}
\hline & & $\begin{array}{l}\text { Time } \\
10 \mathrm{am} \\
\end{array}$ & $11 \mathrm{am}$ & $12 \mathrm{pm}$ & $1 \mathrm{pm}$ & $2 \mathrm{pm}$ & $3 \mathrm{pm}$ & $4 \mathrm{pm}$ \\
\hline \multirow{4}{*}{$\begin{array}{l}\text { Heat flux, } \\
q^{\prime \prime}\left(W / m^{2}\right)\end{array}$} & No ins. & 0.392 & 0.296 & 0.490 & 0.648 & 0.546 & 0.492 & 0.411 \\
\hline & 1 layer & 0.308 & 0.256 & 0.475 & 0.629 & 0.532 & 0.431 & 0.314 \\
\hline & 2 layers & 0.263 & 0.263 & 0.465 & 0.573 & 0.491 & 0.405 & 0.271 \\
\hline & 3 layers & 0.244 & 0.244 & 0.392 & 0.518 & 0.417 & 0.353 & 0.247 \\
\hline
\end{tabular}

Table 4

Comparison between the classroom and the wooden room model in terms of roof area and cost of insulation

\begin{tabular}{lll}
\hline Workshop & Comparison & Wooden room model \\
\hline 1 & Ratio & 4 \\
$3.2 \mathrm{~m} \times 4.8 \mathrm{~m}$ & Roof area & $0.8 \mathrm{~m} \times 1.2 \mathrm{~m}$ \\
RM 6.72 & Cost $(1$ layer- $25 \mathrm{~mm})$ & RM 0.42 \\
RM 13.14 & Cost (2 layers $-50 \mathrm{~mm})$ & RM 0.84 \\
RM 20.16 & Cost (3 layers $-75 \mathrm{~mm})$ & RM 1.26 \\
\hline
\end{tabular}

For the wooden room model, the cost of glass wool insulation increases RM 0.42 for each layer. According to the data tabulated in Figure 6 , the indoor temperature is reduced by $1^{\circ} \mathrm{C}$ at $1 \mathrm{pm}$ after applying one layer of glass wool insulation. If two layers of glass wool insulation is applied on the roof of the wooden room model, the indoor temperature is reduced by $1.3^{\circ} \mathrm{C}$ at a cost of RM 0.84 which means that extra RM 0.42 is spent to further reduce the temperature by $0.3^{\circ} \mathrm{C}$. However, if three layers of glass wool are applied, the indoor temperature is reduced by $1.5^{\circ} \mathrm{C}$ with insulation cost of RM 1.26. The reduction of $0.5^{\circ} \mathrm{C}$ increases the insulation cost to RM 0.84 . If three layers of glass wool are applied to the workshop, the cost in reducing the indoor temperature by $0.5^{\circ} \mathrm{C}$ is $\mathrm{RM} 13.14$. Therefore, the reduction of temperature after applying three layers of glass wool insulation on the roof is not significant and cost effective. According to the equation developed by Indra Mahlia et al., [17], the optimum thickness of glass wool insulation is $66.4 \mathrm{~mm}$. With that, two layers of glass wool insulation with a thickness of $50 \mathrm{~mm}$ is proven to be the optimum thickness in this study.

The cost saving after applying two layers of glass wool insulation can be calculated by using the reduction of heat flux and the medium voltage general commercial tariff set by Tenagah Sdn Bhd. At $1 \mathrm{pm}$, the heat flux of the roof without applying any insulation is $0.648 \mathrm{~W} / \mathrm{m}^{2}$. The heat flux is reduced to $0.573 \mathrm{~W} / \mathrm{m}^{2}$ after applying two layers of glass wool insulation. The cost saving per month is not significant as shown in the calculation above because of a few important factors. Firstly, the roof area 
of the following workshop is not as big as large surface roof area building such as shopping malls, schools, factories, stadium and so on. Therefore, the reduction of heat energy is more when the roof area is huge. Besides, the saving is small because wooden room model is used instead of real room. The cost saving is also purely from the use of thermal insulation itself without any cooling load such as fans and air conditioning. Therefore, for actual room with bricks and cements, the reduction of the heat flux will be increased along with high energy saving [3-5,12].

\section{Conclusion}

The following study is done to determine the optimum thickness of glass wool insulation through experimentation and analysis of the results. Different thickness of glass wool insulation is used to determine the effectiveness of each thickness of glass wool insulation in reducing the temperature inside the wooden room model. The maximum temperature reduction for one layer of glass wool insulation is $1^{\circ} \mathrm{C}$ at a cost of RM 0.42 . When two layers of glass wool insulation are applied, the temperature inside the room is reduced by $1.3^{\circ} \mathrm{C}$ that costs $\mathrm{RM} 0.84$. It shows that an extra $0.3^{\circ} \mathrm{C}$ is reduced with the addition of one layer at a cost of RM 0.42 . As for three layers of glass wool insulation, it costs RM 1.26 to reduce the indoor temperature by $1.5^{\circ} \mathrm{C}$. For three layers of insulation, the temperature inside the room is further reduced by $0.5^{\circ} \mathrm{C}$ with an insulation cost of RM 0.84 on the addition of two layers. In addition to that, the optimum thickness of glass wool insulation is determined by using the polynomial function developed by Indra Mahlia et al., [18] which is $66.2 \mathrm{~mm}$. As a conclusion, two layers of glass wool insulation with a thickness of $50 \mathrm{~mm}$ is proved to be the optimum thickness in this study as it is more cost effective with an ROI of $27.40 \%$ per annum. With that, all the objectives of the study are met.

\section{References}

[1] Halwatura, R. U., and M. T. R. Jayasinghe. "Thermal performance of insulated roof slabs in tropical climates." Energy and Buildings 40, no. 7 (2008): 1153-1160.

https://doi.org/10.1016/j.enbuild.2007.10.006

[2] Tong, Shanshan, Hua Li, Kishor T. Zingre, Man Pun Wan, Victor W-C. Chang, Swee Khian Wong, Winston Boo Thian Toh, and Irene Yen Leng Lee. "Thermal performance of concrete-based roofs in tropical climate." Energy and Buildings 76 (2014): 392-401.

https://doi.org/10.1016/j.enbuild.2014.02.076

[3] Aditya, Lisa, T. M. I. Mahlia, B. Rismanchi, H. M. Ng, M. H. Hasan, H. S. C. Metselaar, Oki Muraza, and H. B. Aditiya. "A review on insulation materials for energy conservation in buildings." Renewable and Sustainable Energy Reviews 73 (2017): 1352-1365. https://doi.org/10.1016/i.rser.2017.02.034

[4] Muhieldeen, Mohammed W., Q. Y. Wong, Ummi Zulaikha Abd Rahman, and Wah Yen Tey. "Energy Saving by Applying Different Wall Thermal Insulations on a Room at Malaysian Institution." Journal of Advanced Research in Fluid Mechanics and Thermal Sciences 65, no. 1 (2020): 130-139.

[5] Muhieldeen, M. W., Y. R. Lim, Sunil Govinda, and Wah Yen Tey. "Investigation of the Effect of Awning using Sunlight Sensor to Reduce Cooling Load in the Room." Journal of Advanced Research in Fluid Mechanics and Thermal Sciences 67, no. 1 (2020): 136-145.

[6] Lai, Chi-ming, J. Y. Huang, and Jenq-Shing Chiou. "Optimal spacing for double-skin roofs." Building and Environment 43, no. 10 (2008): 1749-1754.

https://doi.org/10.1016/i.buildenv.2007.11.008

[7] Muhieldeen, M. W., and Y. C. Kuang. "Saving energy costs by combining air-conditioning and air-circulation using CFD to achieve thermal comfort in the building." Journal of Advanced Research in Fluid Mechanics and Thermal Sciences 58, no. 1 (2019): 84-99.

[8] Lam, Joseph C., C. L. Tsang, Danny HW Li, and S. O. Cheung. "Residential building envelope heat gain and cooling energy requirements." Energy 30, no. 7 (2005): 933-951.

https://doi.org/10.1016/i.energy.2004.07.001 
[9] Yang, Junjing, Andri Pyrgou, Adrian Chong, Mat Santamouris, Denia Kolokotsa, and Siew Eang Lee. "Green and cool roofs' urban heat island mitigation potential in tropical climate." Solar Energy 173 (2018): 597-609. https://doi.org/10.1016/j.solener.2018.08.006

[10] Takebayashi, Hideki, and Masakazu Moriyama. "Relationships between the properties of an urban street canyon and its radiant environment: Introduction of appropriate urban heat island mitigation technologies." Solar Energy 86 , no. 9 (2012): 2255-2262. https://doi.org/10.1016/i.solener.2012.04.019

[11] Yew, M. C., NH Ramli Sulong, W. T. Chong, S. C. Poh, B. C. Ang, and K. H. Tan. "Integration of thermal insulation coating and moving-air-cavity in a cool roof system for attic temperature reduction." Energy Conversion and Management 75 (2013): 241-248.

https://doi.org/10.1016/i.enconman.2013.06.024

[12] Muhieldeen, M. W., N. M. Adam, and B. H. Salman. "Experimental and numerical studies of reducing cooling load of lecture hall." Energy and Buildings 89 (2015): 163-169. https://doi.org/10.1016/i.enbuild.2014.12.026

[13] Ong, Kok Seng. "Temperature reduction in attic and ceiling via insulation of several passive roof designs." Energy Conversion and Management 52, no. 6 (2011): 2405-2411. https://doi.org/10.1016/i.enconman.2010.12.044

[14] Mahlia, T. M. I., and A. Iqbal. "Cost benefits analysis and emission reductions of optimum thickness and air gaps for selected insulation materials for building walls in Maldives." Energy 35, no. 5 (2010): 2242-2250. https://doi.org/10.1016/j.energy.2010.02.011

[15] Salman, B. H., M. Z. Hamzah, J. Purbolaksono, J. I. Inayat-Hussain, H. A. Mohammed, and M. W. Muhieldeen. "Determination of correlation functions of the oxide scale growth and the temperature increase." Engineering Failure Analysis 18, no. 8 (2011): 2260-2271. https://doi.org/10.1016/i.engfailanal.2011.08.001

[16] Sisman, Nuri, Emin Kahya, Nil Aras, and Haydar Aras. "Determination of optimum insulation thicknesses of the external walls and roof (ceiling) for Turkey's different degree-day regions." Energy Policy 35, no. 10 (2007): 51515155. https://doi.org/10.1016/i.enpol.2007.04.037

[17] Ozel, Meral. "Cost analysis for optimum thicknesses and environmental impacts of different insulation materials." Energy and Buildings 49 (2012): 552-559. https://doi.org/10.1016/j.enbuild.2012.03.002

[18] Mahlia, T. M. I., B. N. Taufiq, and H. H. Masjuki. "Correlation between thermal conductivity and the thickness of selected insulation materials for building wall." Energy and Buildings 39, no. 2 (2007): 182-187. https://doi.org/10.1016/i.enbuild.2006.06.002

[19] Incropera, F., D. Dewitt, T. L. Bergman, and Adrienne S. Lavine. Principles of Heat and Mass Transfer. John Wiley \& Sons, 2018.

[20] Qahtan, Abdultawab M. "Thermal performance of a double-skin façade exposed to direct solar radiation in the tropical climate of Malaysia: A case study." Case Studies in Thermal Engineering 14 (2019): 100419. https://doi.org/10.1016/j.csite.2019.100419 